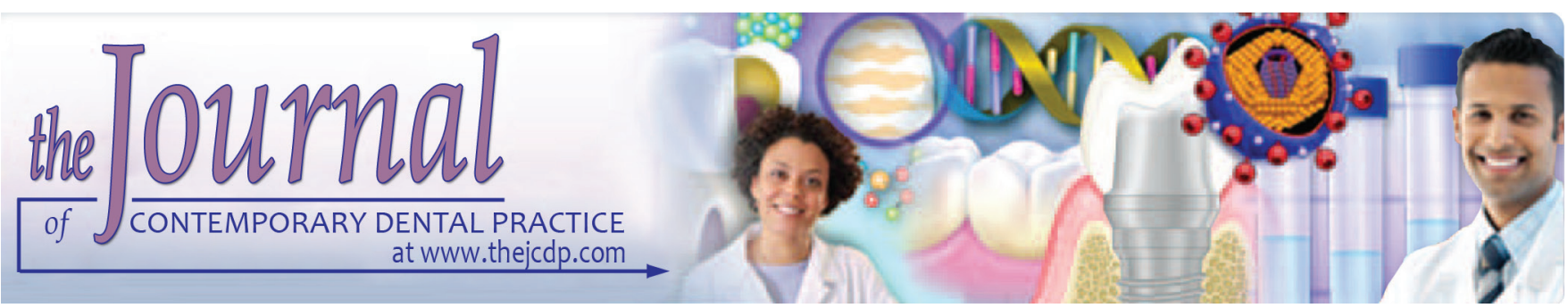

\title{
Effect of Dental Prophylaxis Techniques on the Surface Roughness of Resin Composites
}

\author{
${ }^{1}$ Isabella A Gomes, ${ }^{2}$ Hevylla GGS Mendes, ${ }^{3}$ Etevaldo M Maia Filho, ${ }^{4}$ Cláudia de C Rizzi, ${ }^{5}$ Mario G Nina \\ ${ }^{6}$ Cecilia P Turssi, ${ }^{7}$ Ana JC Vasconcelos, ${ }^{8}$ Matheus C Bandeca, ${ }^{9}$ Rudys R de Jesus Tavarez
}

\begin{abstract}
Aim: The aim of this study is to evaluate the effect of dental prophylaxis techniques on surface roughness of composite resins.

Materials and methods: A total of 36 nanohybrid resin composite test specimens were fabricated and divided into three groups $(n=12)$. They were kept in distilled water at $37^{\circ} \mathrm{C}$ for 24 hours and submitted to the finishing and polishing technique. For the prophylactic techniques, in group $\mathrm{G} 1$, a mixture of pumice stone and distilled water was used with the aid of a rubber cup; in group G2, Herjos-F prophy paste was used with a rubber cup; and in group G3, a bicarbonate jet spray was used. Afterward, all the samples were repolished using the Soflex pop-on disks. A roughness meter was used to measure surface roughness at three points in time: Before the prophylactic techniques (1st evaluation), afterward (2nd evaluation), and following repeat polishing (3rd evaluation).
\end{abstract}

Results: It was found that roughness values changed significantly between the 1 st and 2 nd evaluations $(p<0.05)$ and between the 2nd and 3rd evaluations ( $p<0.05)$, showing that the change in roughness depended on the type of prophylactic treatment. Roughness was significantly higher after the bicarbonate jet $(p<0.05)$.

Conclusion: Prophylaxis using the sodium bicarbonate jet significantly altered the roughness of nanoparticle-reinforced resin.

Clinical significance: Dental prophylaxis is the most common practice employed to remove bacterial plaque and other coatings. However, one side effect of the cleaning may be a rougher surface subject to degradation and staining. The correct use of prophylactic devices and avoiding prolonged use on resin restorations reduce surface roughness.

\footnotetext{
${ }^{1-5,7-9}$ Department of Dentistry, Ceuma University, São Luis Maranhão, Brazil

${ }^{6}$ Department of Dentistry, São Leopoldo Mandic University Campinas, São Paulo, Brazil

Corresponding Author: Rudys R de Jesus Tavarez, Rua Josue Montello 01, Renascença, São Luis, Maranhão, Brazil, Phone: +5598988283948, e-mail: rudysd@uol.com.br
}

Keywords: Composite resins, Dental prophylaxis, Surface roughness.

How to cite this article: Gomes IA, Mendes HGGS, Filho EMM, de C Rizzi C, Nina MG, Turssi CP, Vasconcelos AJC, Bandeca MC, de Jesus Tavarez RR. Effect of Dental Prophylaxis Techniques on the Surface Roughness of Resin Composites. J Contemp Dent Pract 2018;19(1):37-41.

Source of support: Nil

Conflict of interest: None

\section{INTRODUCTION}

In the recent decades, restorative dentistry has made significant advances in the evolution of materials and techniques for restoring shape and function to the dental structure, as well as offering the patient an opportunity to have a more harmonious smile. ${ }^{1}$ One of the materials that has seen great progress is resin composites; these are used in both the anterior and posterior teeth and possess good, mechanical, biological, and physical properties, as well as providing excellent esthetics. ${ }^{2}$

The particle size is hugely important for surface hardness and smoothness; the smoother the surface of resin composite restorations is, the lower is the biofilm adhesion. Better optical and esthetic properties will also be obtained. ${ }^{3}$ Within the evolution of resin composites, at the present time, nanoparticle-reinforced resins are the most noteworthy. These are composed of inorganic substances of nanometric scale and are thus, are very strong and have excellent optical properties. ${ }^{4}$

The success and longevity of resin composite restorations are a function of the material selected, the professional's technical skills, and the patient, who must take responsibility for his/her own oral hygiene, eating habits, and preventive measures, as carious lesions have been one of the causes of replacement of direct resin composites. ${ }^{5,6}$ 


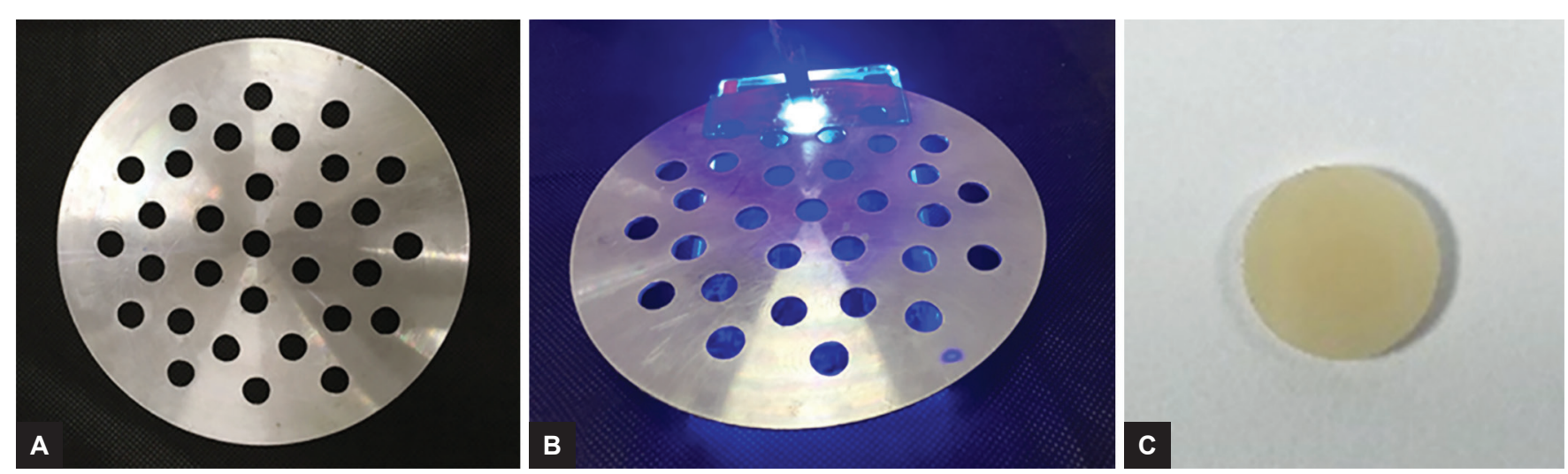

Figs $1 \mathrm{~A}$ to $\mathrm{C}$ : (A and $\mathrm{B}$ ) Metal mold using to fabricate specimens; and $(\mathrm{C})$ resin compost specimen

A great many factors can have an influence on the roughness of resin composites, including size and volume of inorganic matter and size and hardness of the abrasives used in the finishing and polishing techniques. Similarly, the techniques of dental prophylaxis followed by polishing can affect their roughness ${ }^{7}$ and leave a rougher surface, i.e., subject to degradation and staining. ${ }^{8}$ The correct use of prophylaxis devices reduces surface roughness in resin composite restorations. ${ }^{9}$

Pastes of pumice stone and water combined with the rubber cup, prophylaxis pastes, and bicarbonate jet sprays are used to remove dental biofilm and extrinsic stains. These systems are effective in terms of cleaning ability, ${ }^{10}$ but may affect the surface roughness of the resin composites. Given the above, it is necessary to investigate if the different techniques and materials employed for dental prophylaxis on nanoparticle-reinforced resin composite restorations significantly alter the roughness and if repeat polishing is capable of restoring surface smoothness.

\section{MATERIALS AND METHODS}

The sampling calculation was performed with $\alpha=5 \%$ and a test power of $80 \%$ (Biostat 5.0, version 2007), resulting in the recommendation to use 36 test specimens.

\section{Preparation of the Test Specimens}

The test specimens were fabricated in the shape of disks $10 \mathrm{~mm}$ in diameter and $2 \mathrm{~mm}$ thick, using a perforated metal mold (Fig. 1A).

The mold was filled with Opallis nanoparticlereinforced resin composite (FGM, Joinville, Santa Catarina, Brazil), color A2 for enamel, which was pressed using a polyester matrix strip (TDV, Pomerode, Santa Catarina, Brazil), with the assistance of a microscope slide (Labor Import, Osasco, São Paulo, Brazil), producing a smooth resin surface.

The resin was inserted in incremental fashion using a purpose-designed spatula (Prisma, São Paulo, Brazil) and then photopolymerized for 40 seconds per increment (following manufacturer's instructions) using the photopolymerizer Optilight Plus light-emitting diode lightcuring unit (Gnatus, Ribeirão Preto, São Paulo, Brazil) with light intensity measured using a $600 \mathrm{~mW} / \mathrm{cm}^{2}$ Optilight LD radiometer (Gnatus Brasil, Joinville, Santa Catarina, Brazil; Figs 1B and C).

After fabrication, the test specimens were placed at random into plastic containers for examination along with distilled water and stored in a bacteriological incubator for 24 hours at $37 \pm 1^{\circ} \mathrm{C}$.

\section{Finishing/Polishing and Dental Prophylaxis Techniques}

The test specimens were divided at random into three experimental groups, to be submitted to different dental prophylaxis techniques, as shown in Table 1.

All the test specimens were submitted to the finishing and polishing technique (Soflex pop-on abrasive disks-3M, São Paulo, Brazil) for an initial analysis of roughness (Fig. 2A). Three readings were taken for each specimen. During the finishing/polishing procedure, medium- and fine-grit abrasive disks were used with movement in one direction only, and under controlled pressure for 40 seconds, by a single operator (Fig. 2B). The disk change was standardized once for every four resin test specimens.

After the finishing and polishing procedures, an evaluation of roughness was performed (1st reading) using a roughness meter (SJ-210, São Paulo, Brazil). For each specimen, a total of three readings were taken, using

Table 1: Distribution of groups according to polishing treatment order

\begin{tabular}{lllll}
\hline Groups & $n$ & 1st stage & 2nd stage & 3rd stage \\
\hline I & 12 & Soflex fin/pol & $\begin{array}{l}\text { Prophylaxis- } \\
\text { pumice stone }\end{array}$ & Soflex fin/pol \\
II & 12 & Soflex fin/pol & $\begin{array}{l}\text { Prophylaxis- } \\
\text { prophylaxis paste }\end{array}$ & Soflex fin/pol \\
III & 12 & Soflex fin/pol & $\begin{array}{l}\text { Prophylaxis- } \\
\text { bicarbonate jet }\end{array}$ & Soflex fin/pol \\
\hline
\end{tabular}



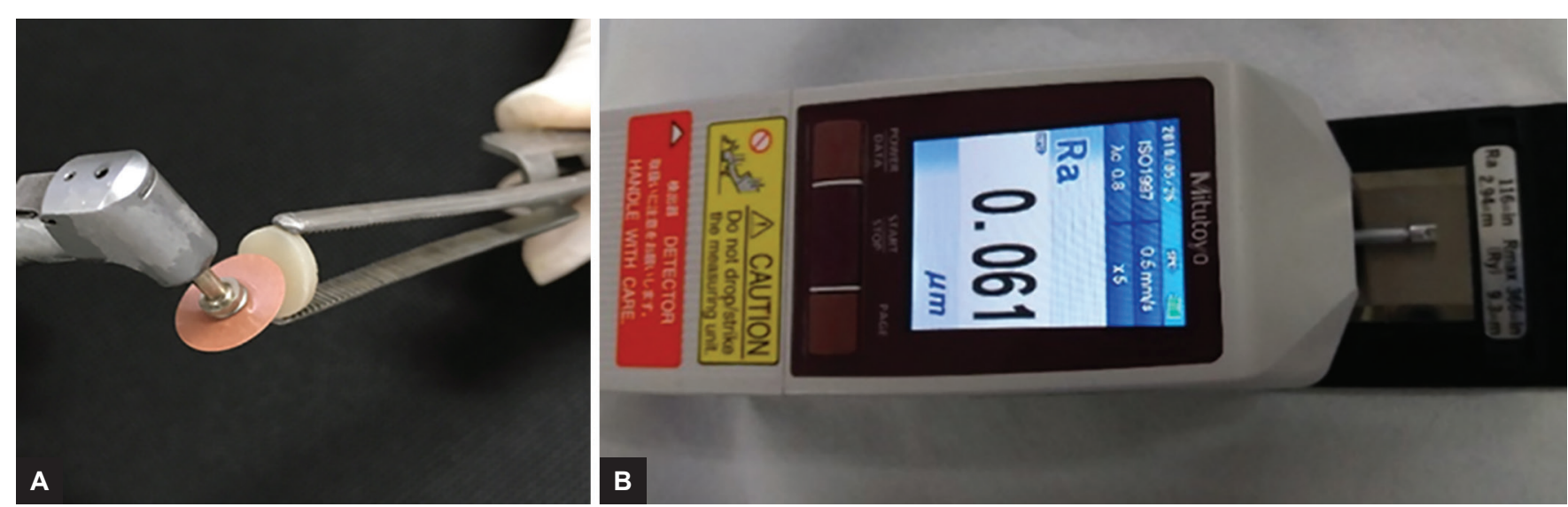

Figs 2A and B: (A) Finish and polish the specimens; and (B) evaluation of roughness using a roughness meter

the average of the values obtained. Subsequently, for each group, different prophylaxis protocols were carried out as follows:

- Group I: Prophylaxis with the aid of a low rpm micromotor (Kavo, Joinville, Brazil), rubber cup (Viking, Curitiba, Brazil), and a mixture of pumice stone (SS White, 3M, Rio de Janeiro, Brazil) and distilled water. The mixture proportion was $60 \mathrm{gm}$ of pumice stone to $50 \mathrm{~mL}$ distilled water, for 10 seconds without interruption.

- Group II: Prophylaxis using Herjos-F prophylaxis paste (Vigodent, Rio de Janeiro, Brazil), for 10 seconds without interruption.

- Group III: Prophylaxis through the application of a sodium bicarbonate jet spray (Profi II - Dabi Atlante, Ribeirão Preto, Brazil). The tip of the jet was set at an approximate distance of $5 \mathrm{~mm}$, as per manufacturer's recommendations, and at an angle of $90^{\circ}$, carried out for 10 seconds without interruption.

At the end, the test specimens were washed in water for 10 seconds using a triple syringe, and then dried with the aid of jets of air for 5 seconds and evaluated for surface roughness, following the same procedure used in the 1st reading (2nd reading). Subsequently, all the test specimens underwent the same finishing and polishing sequences to carry out an evaluation of surface roughness (3rd reading).

\section{Statistical Analysis}

The following hypotheses were tested: (1) Whether the average roughness values changed significantly within the groups, between the 1st and the 2nd evaluations, and between the 2nd and 3rd evaluations, (2) whether there was a significant difference in the average roughness values between the groups before and after prophylaxis and after polishing.

To answer the first hypothesis, repeated measures analysis of variance (ANOVA) was employed, while the second was answered by employing, for each reading period, the one-way ANOVA test, supplemented by the post hoc Tukey test. The level of significance adopted was $5 \%$. The statistical program used was Statistical Package for the Social Sciences version 23.0 (IBM, Armonk, New York, USA).

\section{RESULTS}

The mean and standard deviation values for roughness, after the three roughness readings, are in Table 2.

The repeated measures ANOVA showed that there was a significant change in roughness in the group, which used the bicarbonate jet spray, between the 1st and 2nd readings ( $p=0.008$ ), and between the 2 nd and 3rd readings $(p=0.012)$. There was no difference between readings within the other groups ( $>0.05$; Graph 1$)$.

The one-way ANOVA, used for each reading period, enabled us to ascertain that there was no significant difference between the groups after the initial treatment $(p=0.720)$ and the final treatment with Soflex $(p=0.531)$; however, in the analysis of the 2nd reading, it was found that the roughness was different between groups $(p=0.004)$. The use of the bicarbonate jet spray afforded a significantly higher roughness value than the treatments with prophylaxis paste $(\mathrm{p}=0.005)$ and sodium

Table 2: Mean roughness values (standard deviation) in $\mu \mathrm{m}$, after the different prophylactic treatments

\begin{tabular}{|c|c|c|c|}
\hline \multirow{3}{*}{ Groups } & 1st Reading & 2nd Reading & 3rd Reading \\
\hline & (Post-Soflex) & (Prophylactic treatment) & (Post-Soflex) \\
\hline & & Pumice stone paste & \\
\hline \multirow[t]{2}{*}{ I } & $0.974(0.446)$ & $0.883(0.324)^{a}$ & $0.706(0.403)$ \\
\hline & & Prophylaxis paste & \\
\hline \multirow[t]{2}{*}{ II } & $0.830(0.559)$ & $0.711(0.262)^{a}$ & $0.765(0.486)$ \\
\hline & & Bicarbonate jet & \\
\hline III & $0.839(0.432)$ & $1.61(1.045)^{b}$ & $0.951(0.713)$ \\
\hline
\end{tabular}

Different letters superscript: Statistically significant difference, $p<0.05$ (ANOVA, Tukey test) 


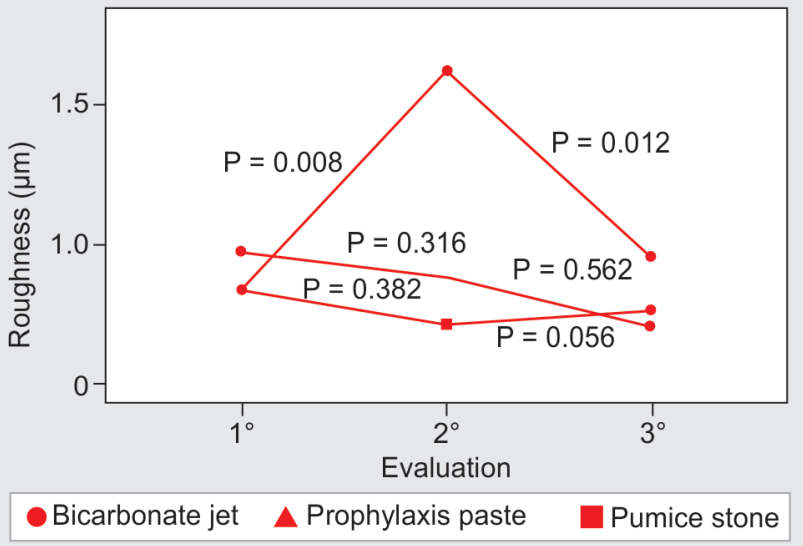

Graph 1: Mean roughness values $(\mu \mathrm{m})$ after different types of surface treatments and the comparisons between readings within the groups with the respective values $(p<0.05$, statistically significant difference)

bicarbonate $(\mathrm{p}=0.025)$; however, there was no significant difference between the prophylaxis paste and the sodium bicarbonate $(p=0.796$; Table 2).

\section{DISCUSSION}

Some of the most important characteristics in restorations in anterior teeth relate to surface roughness. A new type of photoactivated composite resin, known as nanohybrid resin, was recently introduced to the dental marketplace. Its characteristics give the material properties that surpass those of hybrid composites, namely, better polishing, ease of handling, and the ability to preserve the anatomical structure for long periods of time. ${ }^{4}$ Therefore, as a way to keep abreast of the evolution of composite resins, the present study used, for its methodology, a nanohybrid composite resin (Opallis-FGM) ${ }^{6}$

The studies have shown that the percentage of bacterial plaque retained on restored surfaces is higher than on tooth surfaces, and that this deposition provokes the onset of periodontal disease. The finishing and polishing procedures reduce the surface roughness of restoration materials, thereby guaranteeing the oral health of patients and the longevity of the restorative treatment. ${ }^{7}$

In the literature, no standard finishing and polishing technique has been established. In fact, there are many such techniques, with different recommendations for instruments and materials to attain this objective. ${ }^{11}$ Polishing affords greater tolerance of the periodontal tissue to the restorations, ${ }^{12}$ and according to Chung, ${ }^{13}$ these procedures produce reduced roughness, ranging from 26 to $74 \%$. In the present study, Soflex pop-on abrasive disks were used (3M, São Paulo, Brazil) to perform the finishing and polishing techniques, in view of the fact that these mechanisms have demonstrated excellent results in the performance of finishing and polishing with resin composite restorations. ${ }^{5}$

No significant difference was found between the groups that initially underwent finishing and polishing with the Soflex disk when compared with the groups that were repolished after applying the prophylactic methods (Table 2). In this regard, the results obtained by Yap et al, ${ }^{14}$ in their evaluation of the surface roughness of resin composites subjected to finishing and polishing systems, showed that the Soflex abrasive disks promoted greater surface smoothness, corroborating the studies conducted by Da Costa et $\mathrm{al}^{12}$ and Ergücü and Türkün, ${ }^{15}$ where the average polishing with Soflex abrasive disks was higher $(0.470 \mu \mathrm{m})$ than with the enhanced abrasive rubber cups $(1.180 \mu \mathrm{m})$.

As far as the techniques of dental prophylaxis are concerned, the present work found that the use of the bicarbonate jet produced a significantly higher average roughness than the treatments that used prophylaxis paste or pumice stone paste. This finding agrees to the study by Alawjali and $\mathrm{Lui}^{2}$ in which an analysis was carried out for the surface roughness of microhybrid resin composites after the application of the sodium bicarbonate jet spray, demonstrating that all resin composites exhibited a considerable increase in surface roughness over the initial values. The study conducted by $\mathrm{Lu}$ et $\mathrm{al}^{16}{ }^{16}$ however, showed contradictory results, finding greater roughness with the prophylactic treatment carried out with pumice stone instead of the bicarbonate jet.

According to Jost-Brinkmann, ${ }^{17}$ variances may be found in the distance from the tip of the jet or in angularity, depending on the region to be worked, which may interfere with the effectiveness of the outcome. In the literature, we found large variations in both angularity and distance and in Scotti et al, ${ }^{18}$ e.g., an inclination of just $30^{\circ}$.

In terms of the distance from the tip of the bicarbonate jet to the resin surface, differences were found ranging from 3 to $10 \mathrm{~mm}$. The manufacturer recommends a distance of $5 \mathrm{~mm}$ and an angle of between $45^{\circ}$ and $90^{\circ}$. These differences in distance and angularity may in some way influence the results of alteration in the roughness of resin composites. Therefore, within the criteria and in accordance with that which the majority of authors advocate, the present study established a distance of $5 \mathrm{~mm}$ and an angle of $90^{\circ}$ for all the studied samples.

In the present study, the prophylaxis technique that uses the bicarbonate jet afforded a significant increase in surface roughness, thereby demonstrating the need to carry out a repolishing of resin composite restorations. The prophylaxis techniques used were bicarbonate jet and 
rubber cup with pumice stone paste. Surface roughness was evaluated before and after the prophylaxis techniques. The results showed an increase in average surface roughness of the resins after the two prophylaxis techniques. After repolishing, the groups exhibited a decrease in surface roughness, for both of the resins under analysis.

Roeder and Powers ${ }^{9}$ remind us of the correct use of the devices for prophylaxis, avoiding protracted use on restorations and regions of dentin and cement. To reduce surface roughness and marginal seepage, the repolishing of restorations is advocated after prophylaxis as well as the use of surface sealants.

Thus, surface roughness caused by the absence of repolishing after dental prophylaxis could give rise to a buildup of plaque, gum irritation, susceptibility to pigmentation, ${ }^{17}$ increase in the rates of wear and tear, recurrent caries, and impairment of the brightness of the restoration, resulting in a reduced longevity. ${ }^{11}$

Based on the results of this study, it is recommended that, after prophylaxis using bicarbonate jets, pumice stone paste, or prophylaxis paste, resin composite restorations should be subjected to a fresh polishing to restore surface smoothness. Further studies are required using other types of resin, finishing and polishing methods, and prophylaxis techniques.

\section{CONCLUSION}

Based on the methodology employed and noting the results obtained, it may be concluded that:

- Dental prophylaxis techniques do have an influence on the surface roughness of resin composites;

- The bicarbonate jet produces an increase in surface roughness; and

- The repolishing of resin composites significantly reduces alteration in surface roughness.

\section{REFERENCES}

1. da Rosa Rodolpho PA, Cenci MS, DonassolloTA, Loguércio AD, Demarco FF. A clinical evaluation of posterior composite restorations: 17-year findings. J Dent 2006 Aug;34(7): 427-435.

2. Alawjali SS, Lui JL. Effect of one-step polishing system on the color stability of nanocomposites. J Dent 2013 Aug;41(Suppl3): e53-e61.
3. Yazici AR, Tuncer D, Antonson S, Onen A, Kilinc E. Effects of delayed finishing/polishing on surface roughness, hardness and gloss of tooth-coloured restorative materials. Eur J Dent 2010 Jan;4(1):50-56.

4. Mitra SB, Wu D, Holmes BN. An application of nanotechnology in advanced dental materials. J Am Dent Assoc 2003 Oct;134(10):1382-1390.

5. Jefferies SR. Abrasive finishing and polishing in restorative dentistry: a state-of-the-art review. Dent Clin North Am 2007 Apr;51(2):379-397.

6. Köhler B, Rasmusson CG, Odman P. A five-year clinical evaluation of Class II composite resin restorations. J Dent $2000 \mathrm{Feb} ; 28(2): 111-116$.

7. Banerjee A, Hajatdoost-Sani M, Farrell S, Thompson I. A clinical evaluation and comparison of bioactive glass and sodium bicarbonate air-polishing powders. J Dent 2010 Jun;38(6):475-479.

8. Salami D, Luz MA. Effect of prophylactic treatments on the superficial roughness of dental tissues and of two esthetic restorative materials. Pesqui Odontol Bras 2003 Jan-Mar; 17(1):63-68.

9. Roeder LB, Powers JM. Surface roughness of resin composite prepared by single-use and multi-use diamonds. Am J Dent 2004 Apr;17(2):109-112.

10. Carr MP, Mitchell JC, Seghi RR, Vermilyea SG. The effect of air polishing on contemporary esthetic restorative materials. Gen Dent 2002 May-Jun;50(3):238-241.

11. Craig, RG.; O’Brien, WJ.; Powers, JM. Dental materials: properties and manipulation. 7th ed. St Louis (MO): Mosby Year Book; 2000

12. Da Costa J, Ferracane J, Paravina RD, Mazur RF, Roeder L. The effect of different polishing systems on surface roughness and gloss of various resin composites. J Esthet Restor Dent 2007 Aug;19(4):214-224.

13. Chung $\mathrm{KH}$. Effects of finishing and polishing procedures on the surface texture of resin composites. Dent Mater 1994 Sep;10(5):325-330.

14. Yap AU, Yap SH, Teo CK, Ng JJ. Comparison of surface finish of new aesthetic restorative materials. Oper Dent 2004 Jan;29(1):100-104.

15. Ergücü Z, Türkün LS. Surface roughness of novel resin composites polished with one-step systems. Oper Dent 2007 Mar-Apr;32(2):185-192.

16. Lu H, Roeder LB, Lei L, Powers JM. Effect of surface roughness on stain resistance of dental resin composites. J Esthet Restor Dent 2005 Mar;17(2):102-108.

17. Jost-Brinkmann PG. The influence of air polishers on tooth enamel. An in-vitro study. J Orofac Orthop 1998 Jan;59(1): 1-16.

18. Scotti R, Mascellani SC, Forniti F. The in vitro color stability of acrylic resins for provisional restorations. Int J Prosthodont 1997 Mar-Apr;10(2):164-168. 